\title{
GEOGRAPHICAL DISTRIBUTION AND CLUSTER DETECTION OF CHILDHOOD LEUKEMIA IN THE METROPOLITAN AREA OF GUADALAJARA, MEXICO
}

\author{
Alberto Tlacuilo-Parra ${ }^{1}$, Roberto Garibaldi-Covarrubias ${ }^{2}$, Hugo Romo-Rubio ${ }^{2,3}$, \\ Leonardo Soto-Sumuano ${ }^{1,4}$, Carlos Fernando Ruiz-Chávez ${ }^{5}$, Mijail Suárez-ArRedondo ${ }^{1}$, \\ Fernando SÁnchez-Zubieta ${ }^{3}$ and Sergio Gallegos-Castorena ${ }^{3}$ \\ ${ }^{1}$ Medical Research Division and ${ }^{2}$ Pediatric Hematology and Oncology Department, UMAE Hospital de Pediatría CMNO, \\ Instituto Mexicano del Seguro Social (IMSS); ${ }^{3}$ Pediatric Hematology and Oncology Department, Nuevo Hospital Civil \\ de Guadalajara; ${ }^{4}$ Information Systems Department CUCEA, Universidad de Guadalajara, Zapopan; ${ }^{5}$ Information \\ Technology Consultant, Geospatial Data Specialist, Guadalajara, Jal. Mexico
}

\begin{abstract}
Background: Acute leukemia is the most common cancer in childhood. Analyzing the spatial distribution of acute leukemia may generate the identification of risk factors. Objective: To study the incidence rate of acute leukemia, its geographic distribution, and cluster detection in the metropolitan area of Guadalajara, Mexico. Methods: We included children under 15 years of age diagnosed with acute leukemia during the period 2010-2014 in the metropolitan area of Guadalajara. Each case was geo-referenced to street level to latitude and longitude coordinates using Quantum Geographic Information System (QGIS). Spatial clusters were found in the location of the acute leukemia cases applying the Density-Based Spatial Clustering of Applications with Noise (DBSCAN) algorithm with R statistical software. Results: A total of 269 cases of leukemia were registered, 227 (84\%) were acute lymphoblastic leukemia and $42(16 \%)$ acute myeloblastic leukemia. The mean age was $6 \pm 4$ years. The mean incidence of acute leukemia was 6.44 cases/100,000 inhabitants: El Salto 10.12/100,000, Guadalajara 7.55/100,000, and Tlaquepaque $6.74 / 100,000$. The DBSCAN found three clusters, all located within the municipality of Guadalajara. Conclusions: The incidence of acute leukemia in our population is higher than that in Canada and the USA. We found three spatial clusters of childhood acute lymphoblastic leukemia in the municipality of Guadalajara, suggesting the presence of local predisposing factors. (REV INVES CLIN. 2017;69:159-65)
\end{abstract}

Key words: Cancer. Childhood. Density based clustering. Disease mapping. Geographic information system. Leukemia. Spatial epidemiology.

Corresponding author:

*Alberto Tlacuilo-Parra

Monte Olimpo, 1413

Col. Independencia

C.P. 44340, Guadalajara, Jal., México

E-mail: albtlacuilo@yahoo.com

Received for publication: 20-12-2016

Accepted for publication: 10-02-2017 


\section{INTRODUCTION}

Leukemia is the most common type of childhood cancer, accounting for 25 to $35 \%$ of the incidence of all cancers among most populations ${ }^{1}$. The commonest type of childhood leukemia is acute lymphoblastic leukemia (ALL), which occurs in approximately $80 \%$ of leukemia cases, followed by acute myeloid leukemia (AML) and chronic myeloid leukemia, and a few other categories $^{2}$. A worldwide cancer survey in 2012 estimated a higher incidence in developing countries than in developed ones: in Canada, the USA, and the UK, the incidence rates are $5.8,4.6$, and 4.0 per 100,000 inhabitants per year, respectively ${ }^{3}$. It is expected that this disease will continue to increase because the population in these countries is younger and growing ${ }^{3}$. It is anticipated that by 2030 , developing countries will account for $70 \%$ of all childhood cancers, and the cancer-related mortality rate will be $5 / 100,000$ children ${ }^{4}$. A high incidence of ALL has been reported among the Hispanic pediatric population of the USA ${ }^{5}$. The worldwide incidence of ALL varies from 2.0 to 3.5 cases per 100,000 inhabitants per year, whereas in Mexico there are more than $6 / 100,000$ inhabitants per year 6 .

Although the etiology of most childhood leukemia is unknown, several environmental factors have been associated with the disease, including ionizing radiation, non-ionizing radiation, chemicals, pesticides, infections, and parental exposure ${ }^{7-9}$.

Spatial cluster detection is an important tool in cancer surveillance to identify areas of high risk and to generate subsequent hypotheses about cancer etiology. A spatial disease cluster is an area with an unusually elevated disease incidence rate ${ }^{10}$. Reported studies have focused on childhood leukemia because of its relatively high incidence among children compared to other malignant diseases, its apparent tendency to cluster, and the public concern over locally elevated leukemia incidence ${ }^{11,12}$.

In Mexico, geographic information systems (GIS) have rarely been implemented to monitor the spatial dispersion of leukemia. We present the incidence rate, spatial distribution findings, and spatial clustering analysis of acute leukemia (AL) cases among children attending the three main public hospital facilities in the metropolitan area of Guadalajara, Jalisco, Mexico.

\section{MATERIALS AND METHODS}

Guadalajara $\left(20^{\circ} 41^{\prime} \mathrm{N}, 103^{\circ} 21^{\prime} \mathrm{W}\right.$, centroid: -103.33608 20.67627) is located in Jalisco, a state with an estimated population of 7.3 million inhabitants according to the latest census of $2010^{13}$, in the Western region of Mexico. The metropolitan area of Guadalajara consists of eight municipalities: Guadalajara, El Salto, Tlajomulco de Zúñiga, Tlaquepaque, Tonalá, Zapopan, Juanacatlán, and Ixtlahuacan de los Membrillos. The last two municipalities were excluded because of the wide dispersion of the population in their territory.

\section{Study population}

Inclusion criteria for AL cases were: being a child under 16 years of age; living in the metropolitan area of Guadalajara; having been diagnosed with AL, confirmed by bone marrow aspiration and immunophenotypic characterization; and having been diagnosed and treated in a public hospital within the metropolitan area during the period 2010-2014.

\section{Hospitals (National Health Service)}

Medical attention for children with AL is provided by different health institutions; the public health sector treats an estimated $97.5 \%$ of the cases of AL that occur in Mexico City ${ }^{2}$. In the metropolitan area of Guadalajara, children with AL receive services provided by the Unidad Médica de Alta Especialidad (UMAE) Hospital de Pediatría, from Instituto Mexicano del Seguro Social (IMSS) and by other public health services such as the Nuevo Hospital Civil de Guadalajara and the Hospital General de Occidente, which belongs to the Secretaría de Salud Jalisco (SSJ). At present, there is no official hospital-based registry of childhood leukemia cases.

\section{Source of patient data}

In each participating hospital, a pediatric hematologist or onco-hematologist identified the cases of pediatric AL from the hospital-based cancer registry. In addition, the patient's record was reviewed to obtain the clinical variables, diagnosis, and street address.

\section{Diagnosis}

Once a diagnosis of AL was established, a pediatric hematologist or onco-hematologist confirmed the 
Table 1. Demographic characteristics of acute leukemia patients in the participating hospitals

\begin{tabular}{lccc}
\hline & $\begin{array}{c}\text { UMAE Hospital de Pediatría } \\
(\mathrm{n}=\mathbf{1 2 7})\end{array}$ & $\begin{array}{c}\text { Nuevo Hospital Civil } \\
(\mathrm{n}=128)\end{array}$ & $\begin{array}{c}\text { Hospital General de Occidente } \\
(\mathrm{n}=\mathbf{1 4})\end{array}$ \\
\hline $\begin{array}{l}\text { Age (years) } \\
\text { Gender, } \mathrm{n}(\%)\end{array}$ & $6.2 \pm 4.2$ & $7.7 \pm 4.9$ & $10.4 \pm 4.8$ \\
$\quad$ Male & $66(52)$ & $65(51)$ & $8(57)$ \\
$\quad$ Female & $61(48)$ & $63(49)$ & $6(43)$ \\
Classification, $\mathrm{n}(\%)$ & $109(86)$ & $105(82)$ & $13(93)$ \\
$\quad$ ALL & $18(14)$ & $23(18)$ & $1(7)$ \\
AML & & & \\
\hline
\end{tabular}

*Mean age and standard deviation.

ALL: acute lymphoblastic leukemia; AML: acute myeloblastic leukemia.

diagnosis by bone marrow smear. Leukemia cases were grouped according to the morphological classification of the World Health Organization $(\mathrm{WHO})^{14}$ and the International Classification of Childhood Cancer (based on the $2^{\text {nd }}$ Edition of the International Classification of Diseases for Oncology $)^{15}$.

\section{Population}

Data on the size of the baseline population was obtained from the 2010 census for Jalisco from the Instituto Nacional de Estadística y Geografía (INEGI). Guadalajara had a population of 1.4 million inhabitants, Zapopan 1.2 million, Tlaquepaque 608,000, Tonalá 478,000, Tlajomulco 416,000, and El Salto 138,000 . All these areas together were designated as the metropolitan area of Guadalajara for this study. Twenty-nine per cent of the population was made up of children 14 years of age or younger ${ }^{13}$.

\section{Spatial data analysis}

Each case was geo-referenced to the street level to latitude and longitude coordinates using Quantum Geographical Information System (QGIS), by matching the addresses with imagery and other documental sources such as printed maps. Spatial analysis was performed in the AL cases dataset to find clusters according to their location using the Density-Based Spatial Clustering of Applications with Noise (DBSCAN) ${ }^{16-18}$ algorithm on R statistical software ${ }^{19,20}$ using the flexible procedures for clustering package ${ }^{21}$. This algorithm identifies clusters by finding point subsets, which have a minimum number of points that are density-connected from each point's neighborhood within a given radius. Points that do not belong to any cluster (e.g., sparse or isolated points) are discarded.
The Agglomeration Geographic Basic Statistics (AGEB) of INEGI consists of the branch municipalities or delegations that make up the country. Its usefulness lies in allowing the formation of primary sampling units and the organization of statistical information. The AGEB has three main attributes: it is easily recognizable in the field to be bound by identifiable and enduring topographic features; it is generally homogeneous in terms of geographic, economic, and social characteristics; and the extension is such that it can be covered by a single person, and thereby used to quantify and characterize the urban population ${ }^{13}$.

The research protocol was approved by the Ethics and Research Committee of the IMSS and the review board of the participating hospitals.

\section{RESULTS}

\section{Demographic findings}

During the study period 2010-2014, 269 childhood $\mathrm{AL}$ cases were treated among the three hospitals, distributed as follows: Nuevo Hospital Civil de Guadalajara 128 cases (47.5\%); UMAE Hospital de Pediatría 127 cases (47.2\%); and Hospital General de Occidente 14 cases (5.2\%). Of the 269 cases, 138 were boys (51\%) and 131 were girls (49\%). Of the 269 patients, 227 (84\%) had ALL, and 42 (16\%) had AML. Table 1 shows the clinical characteristics of patients among the participating hospitals.

\section{Disease mapping}

The overall incidence rate of $\mathrm{AL}$ in the metropolitan area of Guadalajara was $6.44 / 100,000$ persons per 
Table 2. Population, patients, and incidence by municipalities composing the metropolitan area of Guadalajara

\begin{tabular}{|c|c|c|c|c|}
\hline Municipality & $\begin{array}{l}\text { Leukemia } \\
\text { (n, cases) }\end{array}$ & $\begin{array}{l}\text { Population } \\
\quad(n, \ln h)\end{array}$ & Incidence* & $\begin{array}{l}\text { Density } \\
\left(\operatorname{lnh} / \mathrm{km}^{2}\right)\end{array}$ \\
\hline El Salto & 14 & 138,226 & 10.12 & $1,573.3$ \\
\hline Guadalajara & 113 & $1,495,189$ & 7.55 & $9,874.4$ \\
\hline Tlajomulco de Zúñiga & 24 & 416,626 & 5.76 & 583.5 \\
\hline Tlaquepaque & 41 & 608,114 & 6.74 & $5,506.2$ \\
\hline Tonalá & 18 & 478,689 & 3.76 & $2,881.9$ \\
\hline Zapopan & 59 & $1,243,756$ & 4.76 & $1,068.9$ \\
\hline
\end{tabular}

*Incidence rates are per 100,000 persons per year. Inh: inhabitants.

year. The highest rate, of $10.12 / 100,000$ persons per year was found in the municipality of El Salto, followed by Guadalajara with 7.55/100,000 persons per year, and Tlaquepaque with $6.74 / 100,000$ persons per year. The population and incidence rates are summarized by municipality in table 2 , figure 1 .

\section{Clustering analysis}

Figure 2 shows the geographic distribution of childhood $\mathrm{AL}$ and three significant density-based spatial clusters for ALL cases within the municipality of Guadalajara, where the incidence rate was 7.55/100,000 inhabitants per year. Cluster 1 was composed of 23 patients, cluster 2 of 31 , and cluster 3 of 33 . Because of the dispersion of the AML cases and the small number of cases, no spatial clusters were found.

\section{DISCUSSION}

In Mexico City, as in this study of Guadalajara, the overall incidence of childhood leukemia is higher than that reported for other countries. For cities in Canada, the USA, and the UK, the incidence rates are 5.8, 4.6, and 4.0 per 100,000 inhabitants per year, respectively ${ }^{3}$, whereas for the whole metropolitan area of Guadalajara, it was 6.4 cases per 100,000 inhabitants per year. This is similar to data published by IMSS for the years $1996-2002^{6}$, determining the figure to be $5.5 / 100,000$ and more recently for the years 2006$2007^{2}$, with the figure of $5.7 / 100,000$. It is surprising that the high incidence reported for children from Mexico City and Costa Rica ${ }^{22}$, and for Hispanic children in Florida ${ }^{23}$ and Los Angeles ${ }^{24}$ in the USA is of lymphoid leukemia. This finding is interesting because other populations from Latin America, such as El Salvador $^{25}$, Argentina ${ }^{26}$, and Brazil ${ }^{27}$ do not have higher incidences of ALL than do populations of Caucasian origin. This high incidence may have been due to genetic or environmental factors, including ionizing radiation ${ }^{28}$, non-ionizing radiation ${ }^{29}$, pesticides ${ }^{30}$, parental exposure ${ }^{8}$, and infections ${ }^{9}$.

Historically, maps have been the primary source for communicating spatial information; the most famous example of disease mapping is John Snow's mapping of cholera cases in 1854 in London. Geographic location of disease cases can be a crucial first step in identifying and eventually preventing the source of disease outbreaks. The GIS may be used to manage the modeling and mapping of disease, to develop a new hypothesis in a geographic context, to analyze and predict future disease risks, and to undertake location/allocation analysis on the distribution of services and resources ${ }^{31,32}$.

Mapping of disease data can lead to discoveries of patterns, ranging from clusters to uniformly spaced data or to randomly distributed data ${ }^{33}$. Specifically, the analyses of disease distribution and patterns are used within the study of $A L$ research for different purposes: spatial distribution analysis of incidence and prevalence rates for diverse ethnic population groups $^{34-36}$, mapping and analysis of hotspots for disease occurrence ${ }^{37,38}$, or analysis of clusters ${ }^{39-41}$.

The term "cancer cluster" typically implies that more cases of cancer, usually of the same type, are identified within a certain group of people, geographic area, and time period than are expected, based upon the size and age of the population ${ }^{42}$. Analyses of spatial clusters are based on Tobler's first law of geography, stating 
Figure 1. Spatial distribution of the 269 cases of childhood AL in the metropolitan area of Guadalajara. Each municipality is branched homogeneously in terms of geographical, economic, and social characteristics. AGEB: agglomeration geographic basis statistics

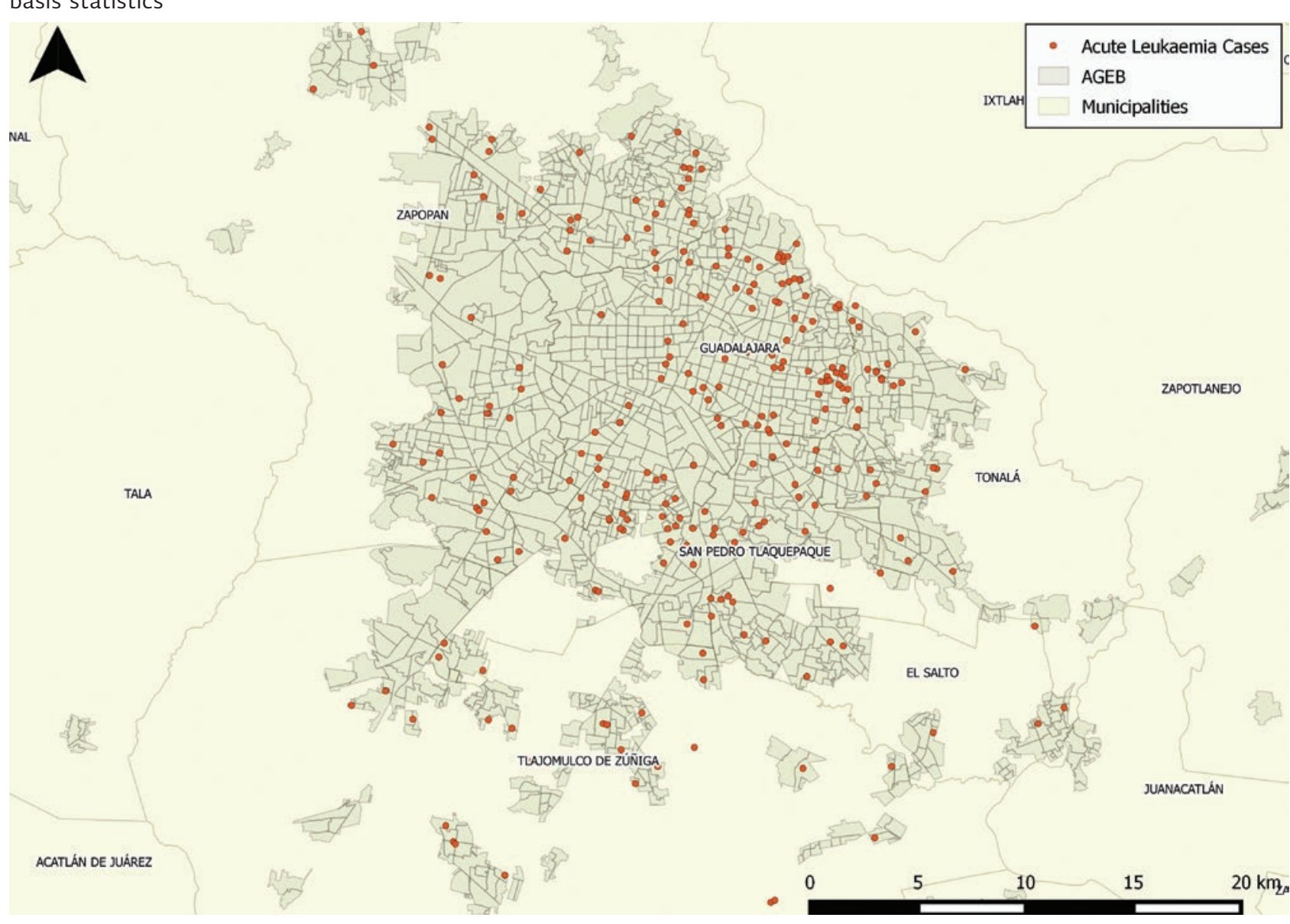

that things that are closer to each other are more alike than things that are further apart ${ }^{43}$. Tobler's law has been used as the basis for analysis of disease, as people who live next to each other tend to be exposed to the same factors that promote certain diseases; hence, the analysis of disease patterns and the hazards of disease clusters can help to determine the causality for disease outbreaks. Some of the environmental exposures that have been putatively linked to the etiology of AL may exhibit geographic variation. These include ionizing radiation, electromagnetic fields, chemical exposure, contaminated drinking water, and infections ${ }^{7}$.

If any of these exposures do play a role in etiology, then the distribution of cases of childhood AL may be predicted to exhibit spatial heterogeneity. This is still a matter of debate; while studies from the UK $^{44}$, Greece ${ }^{45}$, Hong Kong ${ }^{46}$, and Europe ${ }^{47}$ have found statistically significant clustering among cases of childhood AL, studies from England ${ }^{48}$, Sweden ${ }^{49}$, Germany ${ }^{50}$, and France ${ }^{51}$ showed no evidence of spatial clusters of childhood AL. In our study, we found three clusters of ALL in the metropolitan area of Guadalajara over a period of four years.

A number of statistical methods have been developed to test for spatial clustering; Alexander and Boyle evaluated the empirical performance of a number of methods for detecting spatial clustering, including those developed by Black, et al., Potthoff and Whittinghill, Cuzick and Edwards, Openshaw, Besag and Newell, Diggle and Chetwynd, Anderson and Titterington, and Oliver, et al. ${ }^{52}$. In this study, we decided to use the DBSCAN algorithm because it can identify clusters of arbitrary shapes based on density by the minimum number of points and the maximum distance of a point neighborhood, while performing the entire process in a reasonable period of time. 
Figure 2. Three significant density-based spatial clusters of childhood ALL, each composed of at least 15 cases with a maximum distance between cases less than 2,000 meters. AGEB: agglomeration geographic basis statistics

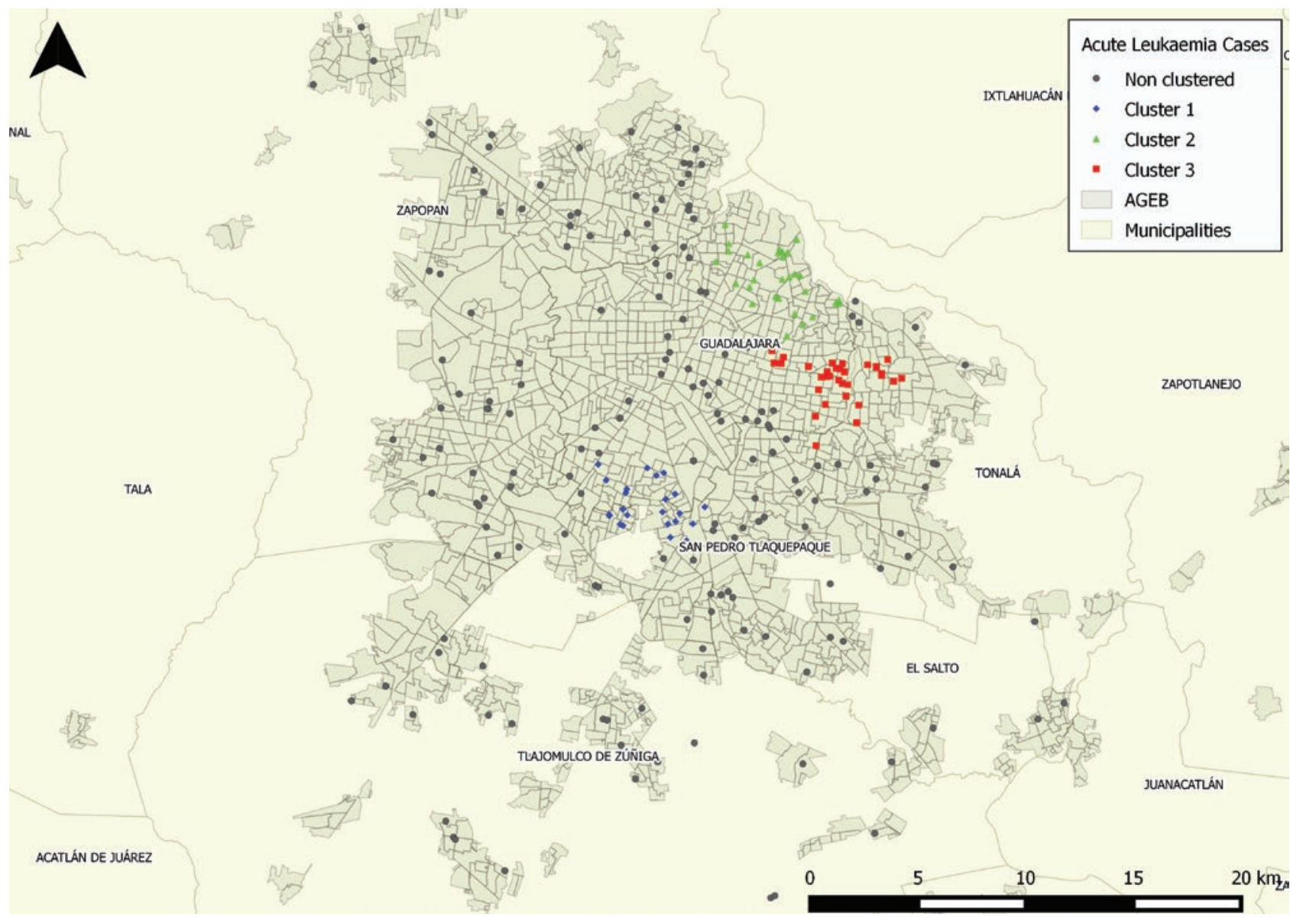

\section{STRENGTHS AND WEAKNESSES OF THE STUDY}

It is important to note that the spatial clusters found on the geographic distribution of ALL cases could have arisen by chance or be explained by lifestyle factors, residential area characteristics, or other unmeasured heterogeneous geographic factors. Spatial clusters are likely to occur in the presence of an environmental exposure persisting over a long period of time. This paper describes the first analysis performed to identify spatial clusters of childhood ALL in Mexico.

\section{ACKNOWLEDGEMENTS}

The authors thank Professor Mark Vinson Jones for translation and proofreading services, and for his helpful comments on the manuscript draft that led to improvement of this article.

\section{CONFLICT OF INTEREST}

Data used in this study by the Hospital General de Occidente were kindly shared from Seguro Popular. Use of these data does not imply that Seguro Popular either agrees or disagrees with the analyses, interpretations or conclusions obtained.

\section{REFERENCES}

1. Cole $\mathrm{CH}$. Lessons from 50 years of curing childhood leukemia. J Paediatr Child Health. 2015;51:78-81.

2. Perez-Saldivar ML, Fajardo-Gutierrez AF, Bernaldez-Rios R, et al. Childhood acute leukemias are frequent in Mexico City: descriptive epidemiology. BMC Cancer. 2011;11:355.

3. Ferlay J, Soerjomataram I, Ervik M, et al. GLOBOCAN 2012 v1.0 Cancer Incidence and Mortality Worldwide: IARC Cancer Base No. 11 Lyon, France: International Agency for Research on Cancer; 2013. 
4. Perez-Cuevas R, Doubova SV, Zapata-Torres M, et al. Scaling up cancer care for children without medical insurance in developing countries: the case of Mexico. Pediatr Blood Cancer. 2013;60: 196-203.

5. Wilkinson JD, Gonzalez A, Wohler-Torres B, et al. Cancer incidence among Hispanic children in the United States. Rev Panam Salud Publica. 2005;18:5-13.

6. Fajardo-Gutierrez A, Juarez-Ocaña S, Gonzalez-Miranda G, et al. Incidence of cancer in children residing in ten jurisdictions of the Mexican Republic: importance of the cancer registry (a population based study). BMC Cancer. 2007:7:68

7. Belson M, Kingsley B, Holmes A. Risk factors for acute leukemia in children: a review. Environ Health Perspect. 2007;115:138-45.

8. Perez-Saldivar ML, Ortega-Alvarez MC, Fajardo-Gutierrez A, et al. Father's occupational exposure to carcinogenic agents and childhood acute leukemia: a new method to assess exposure (a case control study). BMC Cancer. 2008;8:7

9. McNally RJ, Eden TO. An infectious aetiology for childhood acute leukaemia: a review of the evidence. $\mathrm{Br} J$ Haematol. 2004;127: 243-63.

10. Dockerty JD, Sharples KJ, Borman B. An assessment of spatial clustering of leukemias and lymphomas among young people in New Zealand. J Epidemiol Community Health. 1999;53:154-8.

11. Demoury C, Goujon-Bellec C, Guyot-Goubin A, Hemon D, Clavel J. Spatial variations of childhood acute leukemia in France, 1990-2006: global spatial heterogeneity and cluster detection at "living-zone" level. Eur J Cancer Prev. 2012;21:367-74.

12. Nyari TA, Ottoffy G, Bartyik K, et al. Spatial clustering of childhood acute lymphoblastic leukemia in Hungary. Pathol Oncol Res. 2013;19:297-302.

13. Instituto Nacional de Estadistica y Geografia (INEGI): Conteo de población y vivienda 2010. Available at: http://inegi.org.mx/ sistemas/mexicocifras

14. Swerdlow SH, Campo E, Harris NL, et al Eds. In: WHO classification of tumours of haematopoietic and lymphoid tissues. World Health Organization, International Agency for Research on Cancer 2008. Lyon.

15. Kramarova E, Stiller CA. The International Classification of Childhood Cancer. Int J Cancer 1996:68:759-65.

16. Ester M, Hans-Peter K, Jörg S, Xiaowei X. In: Evangelos S; Jiawei $H$, Usama F, Eds. A density-based algorithm for discovering clusters in large spatial databases with noise. Proceedings of the Second International Conference on Knowledge Discovery and Data Mining (KDD-96) 1996. AAAI Press. 226-31.

17. Vander Kelen PT, Downs JA, Stark LM, Loraamm RW, Anderson $\mathrm{JH}$, Unnasch TR. Spatial epidemiology of eastern equine encephalitis in Florida. Int J Health Geogr. 2012;11:47.

18. Guo D, Zhou H, Zou Y, et al. Geographical analysis of the distribution and spread of human rabies in China from 2005 to 2011. PLoS One. 2013;8:e72352.

19. Lock EF, Dunson DB. Bayesian consensus clustering. Bioinformatics. 2013;29:2610-16.

20. R Core Team. A language and environment for statistical computing. R Foundation for Statistical Computing 2015, Vienna, Austria. Available at: http://www.R-project.org/.

21. Henning C. FPC. Flexible procedures for clustering. R package version 2.1-10 2015. Available at: http://CRAN.R-project.org/ package $=f p c$.

22. Monge $P$, Wesseling $C$, Rodriguez AC, et al. Childhood leukaemia in Costa Rica, 1981-96. Paediatr Perinat Epidemiol. 2002;16: 210-18.

23. Wilkinson JD, Fleming LE, MacKinnon J, et al. Lymphoma and lymphoid leukemia incidence in Florida children: ethnic and racial distribution. Cancer. 2001;91:1402-8

24. Glazer ER, Perkins Cl, Young JL Jr, Schlag RD, Campleman SL, Wright WE. Cancer among Hispanic children in California, 19881994: comparison with non-Hispanic white children. Cancer. 1999;86:1070-9

25. Mejia-Arangure JM, Bonilla M, Lorenzana R, et al. Incidence of leukemias in children from El Salvador and Mexico City between 1996 and 2000: population-based data. BMC Cancer. 2005;5:33.

26. Drut R, Hernandez A, Pollono D. Incidence of childhood cancer in La Plata, Argentina, 1977-1987. Int J Cancer. 1990;45:1045-7.

27. De Camargo B, de Oliveira Santos M, Rebelo S, et al. Cancer incidence among children and adolescents in Brazil: first report of 14 population-based cancer registries. Int J Cancer. 2010;126:715-20.

28. Wakeford R. The risk of childhood leukemia following exposure to ionizing radiation, a review. J Radiol Prot. 2013;33:1-25.
29. Hauri DD, Spycher B, Huss A, et al. Exposure to radio-frequency electromagnetic fields from broadcast transmitters and risk of childhood cancer: a census-based cohort study. Am J Epidemiol. 2014;179:843-51.

30. Freedman MD, Stewart P, Kleinerman RA, et al. Household solvent exposures and childhood acute leukemia. Am J Public Health. 2001:91:564-7.

31. Jarup L. Health and environment information systems for exposure and disease mapping, and risk assessment. Environ Health Perspect. 2004;112:995-7.

32. Lyseen AK, Nohr C, Sorensen EM, et al. IMIA Health GIS Working Group. A review and framework for categorizing current research and development in health related geographical information system (GIS) studies. Yearb Med Inform. 2014:9:110-24.

33. Fradelos EC, Papathanasiou IV, Mitsi D, Tsaras K, Kleisiaris CF, Kourkouta $L$. Health based geographical information systems (GIS) and their applications. Acta Inform Med. 2014;22:402-5.

34. Alrudainy LA, Hassan JG, Salih HM, Abbas MK, Majeed AA. Time trends and geographical distribution of childhood leukemia in Basrah, Iraq, from 2004 to 2009. Sultan Qaboos Univ Med J. 2011:11:215-20

35. Geraci M, Eden TO, Alston RD, Moran A, Arora RS, Birch JM Geographical and temporal distribution of cancer survival in teenagers and young adults in England. Br J Cancer. 2009;101: 1939-45.

36. Hjalmars U, Gustafsson G. Higher risk for acute childhood lymphoblastic leukemia in Swedish population centres 1973-94 Swedish child leukaemia group. Br J Cancer. 1999:79:30-3.

37. Jeffery C, Ozonoff A, Pagano M. The effect of spatial aggregation on performance when mapping a risk of disease. Int J Health Geo. 2014;13:9.

38. Ruktanonchai CW, Pindolia DK, Striley CW, Odedina FT, Cottler LB. Utilizing spatial statistics to identify cancer hot spots: a surveillance strategy to inform community-engaged outreach efforts. Int J Health Geogr. 2014;13:39.

39. Amin R, Bohnert A, Holmes R, Rajasekaran A, Assanasen C Epidemiologic mapping of Florida childhood cancer clusters. Pediatr Blood Cancer. 2010;54:511-18.

40. Francis SS, Selvin S, Yang W, Buffler PA, Wiemels JL. Unusual space-time pattering of the Fallon, Nevada leukemia cluster: evidence of an infectious etiology. Chem Biol Interact. 2012;196:102-9.

41. Wheeler DC. A comparison of spatial clustering and cluster detection techniques for childhood leukemia incidence in Ohio, 1996-2003. Int J Health Geogr. 2007;6:13.

42. Thun MJ, Sinks T. Understanding cancer clusters. CA Cancer Clin. 2004;54:273-80.

43. Sui DZ. Tobler's first law of geography: a big idea for a smal world? Ann Assoc Am Geogr. 2004:94:269-77.

44. Knox EG, Gilman E. Leukemia clusters in Great Britain. 2. Geographical concentrations. J Epidemiol Community Health. 1992; 46:573-6.

45. Petridou E, Alexander FE, Trichopoulos D, et al. Aggregation of childhood leukemia in geographic areas of Greece. Cancer Causes Control. 1997;8:239-45.

46. Alexander FE, Chan LC, Lam TH et al. Clustering of childhood leukaemia in Hong Kong: association with the childhood peak and common acute lymphoblastic leukaemia and with population mixing. Br J Cancer. 1997;75:457-63.

47. Alexander FE, Boyle P, Carli PM, et al. Spatial clustering of childhood leukaemia: summary results from the EUROCLUS project. Br J Cancer. 1998;77:818-24.

48. McNally RJ, Alston RD, Cairns DP, Eden OB, Birch JM. Geographical and ecological analyses of childhood acute leukaemias and lymphomas in north-west England. $\mathrm{Br} \mathrm{J}$ Haematol. 2003;123:60-5.

49. Hjalmars U, Kulldorff M, Gustafsson G, Nagarwalla N. Childhood leukemia in Sweden: using GIS and a spatial scan statistic for cluster detection. Stat Med. 1996;15:707-15.

50. Schmiedel S, Blettner M, Kaatsch P. Schuz P. Spatial clustering and space-time clusters of leukemia among children in Germany, 1987-2007. Eur J Epidemiol. 2010;25:627-33.

51. Bellec S, Hemon D, Rudant J, Goubin A, Clavel J. Spatial and space-time clustering of childhood acute leukaemia in France from 1990 to 2000: a nationwide study. $\mathrm{Br}$ J Cancer. 2006;94:763-70.

52. Alexander FE, Boyle P, Eds. Methods for investigating localized clustering of diseases. IARC Scientific Publications 1996 No. 135, Lyon. 